\title{
Culturally responsive student assessment and quality work in higher education
}

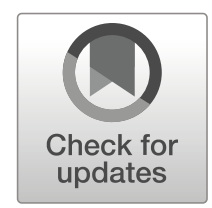

\author{
Guri Skedsmo ${ }^{1,2} \cdot$ Stephan Gerhard Huber ${ }^{3}$
}

Published online: 6 March 2020

(C) Springer Nature B.V. 2020

This issue of EAEA focuses on two topics. The first one relates to assessment systems and practices involving students with migrant or indigenous backgrounds. The two articles addressing this topic contribute to the field called culturally responsive assessment (CRA) (Hood 1998). CRA refers to assessment designs, processes and outcomes, as well as adaptation to individual students and classrooms in ways that are sensitive to cultural variations in thinking, learning and participating. The first article addresses the topic by researching international literature in this field, whereas the second article analyses an empirical study of policies and standardised assessment in Australia.

The second topic concerns quality work in higher education institutions (HEIs). Quality work in this context means a set of activities, practices and tools assessing the quality of educational provision (Lawrence et al. 2013) and may represent a promising way to complement existing analyses that apply perspectives such as quality management and quality culture (Elken and Stensaker 2018). Two empirical studies of key actors' perspectives and beliefs are presented to address this second topic - one study from the higher education context in Bangladesh and one study on higher education in Norway.

\section{Articles in this issue of EAEA, 1/2020}

In the first article, Nortvedt, Wiese, Brown, Burns, McNamara, O'Hara, Altrichter, Fellner, Herzog-Punzenberger, Nayir and Taneri report on their findings from a

Guri Skedsmo

guri.skedsmo@phsz.ch

$\square$ Stephan Gerhard Huber

stephan.huber@phzg.ch

1 Institute for Research on Professions and Professional Learning, Schwyz University of Teacher Education, Goldau, Switzerland

2 Department of Teacher Education and School Research, University of Oslo, Oslo, Norway

3 Institute for the Management and Economics of Education, University of Teacher Education Zug, Zug, Switzerland 
literature review of how migrant students are affected by summative and formative assessment at the classroom level, with a focus on CRA. The background of the review is the trend of increasing migration in recent years, especially in Europe, and the challenges that the school system and educators face regarding handling increasing diversity in schools. Moreover, by bringing together existing knowledge from two different fields, namely multi-cultural education and assessment, the authors contribute to a better understanding of how CRA can be achieved in multi-cultural education settings. The authors identify the following four broad themes which represent the challenges linked to the assessment of migrant students: 1) policy and standardisation, 2) teachers' and students' beliefs and conceptions of competence, 3) communication and participation and 4) student background. Each of these themes may influence the validity and reliability of classroom-level assessment. For instance, both student's and teacher's beliefs about teaching and learning might negatively affect migrant students' opportunities to engage in assessment situations. The authors propose that what is generally considered a valid and reliable assessment practice might need to be adjusted to account for students' cultural ways of knowing and participating and how these are expressed and communicated within the classroom.

In the second article, Cumming, Goldstein and Hand present findings from their analysis of reading and numeracy data (years 3 and 5) from the National Assessment Plan (NAPLAN), as well as school and student information for a single-student cohort from Queensland, Australia, to examine student achievement and progress over time. A special focus of the analyses is the achievement of Australian indigenous and nonindigenous students. The authors refer to 'closing the gap' as the core Australian education equity policy, in which NAPLAN data are used as a primary indicator of policy impact on student outcomes; the authors state that both international and national data show the considerable achievement gap between these student groups. Their analyses demonstrate that this gap between Australian indigenous and nonindigenous students' progress increases as they move through the school system. Interestingly, they also find that the level of achievement within the indigenous student cohort becomes more diverse over time, and the authors consider several policy implications.

In the third article, Rahnuma addresses the critical factors in developing a quality culture in higher education in Bangladesh. The author states that ensuring the quality of programmes meets local and international standards has become a major challenge in many countries (Organisation for Economic Co-operation and Development and World Bank, 2007), especially in South Asian nations. The author emphasises that higher education policymaking in Bangladesh is currently focused on strengthening quality assurance (QA) policies, evolving from relevant national educational legislation and directives to pave the way for the formation of a national accreditation body for Bangladeshi HEIs. Introduced in 2014, Bangladesh's QA mechanisms are still in the process of being fully implemented across every HEI through the establishment of Institutional Quality Assurance Cells, which are guided by the Quality Assurance Unit under Bangladesh's University Grants Commission. Taking a social practice approach to evaluation, which implies considering the evolution of a quality culture in a setting where multiple stakeholders operate and respond to state policies, the author finds that key stakeholders not only emphasise general factors, such as professional autonomy, but also enhance staff capacity building and participation, which are important to 
develop ownership of QA systems and increased accountability. Without a focus on developing ownership by the stakeholders in the QA process, there is a risk that QA procedures will end up as an empty bureaucratic exercise which has little impact on quality enhancement.

In the fourth article, Borch, Sandvoll and Risør focus on the student evaluation of teaching as a multipurpose tool to ensure and improve quality in higher education in Norway. From their analyses, they raise questions with respect to the robustness of using evaluation data for these purposes. Their findings show that the evaluation questions in surveys are mostly teaching oriented, non-specific and satisfaction based; they also do not request feedback from students about the aspects they consider relevant for their learning process. By contrast, more dialogue-based evaluation methods seem to engage students in discussions about their learning and increase students' and teachers' awareness of how improvement efforts could foster or hinder students' learning. Whereas students expected all evaluations to be learning oriented and were surprised by the teaching focus in the surveys, the teachers emphasised that the students might be experts in their own learning but not in the teaching provided in the courses. This discrepancy caused a gap between students' expectations and the experienced evaluation practice. For instance, unclear and non-specific questions that are open for interpretation are not considered relevant for the future action of improving teaching or learning and could decrease students' motivation to respond to such evaluations.

\section{Some reflections}

Both articles by Nortvedt et al. and Cumming et al. emphasise that work remains to be done to ensure that curriculum, teaching and assessment practices provide equal opportunities and enhance equitable education for both migrant and indigenous students. Furthermore, based on the argumentation of the Australian authors, identifying the range of achievement levels within various groups of students and generally paying attention to and supporting all students who struggle are important.

The last article by Borch et al. raises questions about multipurpose tools aiming at ensuring and improving quality in higher education and whether student satisfaction with the teaching offered in programmes and modules represents a sufficient quality measure. Taking a quality work perspective (cf. Elken and Stensaker 2018) implies considering the student perspective, as Borch et al. suggest, and agreeing on notions about quality in higher education in a specific institutional context as the first step towards providing meaningful information and aligning QA practices. Such an institutional perspective contrasts with the elements of QA framed within neoliberal perspectives, which highlight concepts promoted by the globalisation of higher education, such as benchmarking, ranking lists and competition. In the third article about QA in higher education in Bangladesh, Rahnuma has an important point about these concepts which originate from higher education contexts in western countries and are being introduced to South East Asian universities together with pressure to compete. QA procedures therefore need to consider and align institutional and regional concerns as well as measures taken to improve the universities' global standing. 


\section{References}

Elken, M., \& Stensaker, B. (2018). Conceptualising 'quality work' in higher education. Quality in Higher Education, 24(3), 189-202.

Hood, S. (1998). Culturally responsive performance-based assessment: conceptual and psychometric considerations. Journal of Negro Education, 67(3), 187-196.

Lawrence, T. B., Leca, B., \& Zilber, T. B. (2013). Institutional work: current research, new directions and overlooked issues. Organization Studies, 34(8), 1023-1033.

Publisher's note Springer Nature remains neutral with regard to jurisdictional claims in published maps and institutional affiliations. 